\title{
LAS CÉLULAS MADRE COMO POSIBLES HERRAMIENTAS TERAPÉUTICAS PARA LA DEGENERACION RETINIANA
}

\section{STEM CELLS AS PROSPECTIVE THERAPEUTIC TOOLS FOR RETINAL DEGENERATION}

\author{
MARIGO V ${ }^{1}$
}

En los últimos años las células madre han atraído mucho interés como posibles herramientas para el tratamiento de enfermedades y lesiones en humanos. Las enfermedades de degeneración retiniana tales como la retinosis pigmentaria (RP) y la degeneración macular asociada a la edad (DMAE) tienen un dramático impacto socio-económico en nuestra sociedad. La RP es una enfermedad genéticamente heterogénea y, hasta ahora, alrededor de 34 genes han sido asociados con ella. Por otro lado, factores tanto genéticos como ambientales coadyuvan como causas de DMAE. Debido a la diversidad genética y funcional de las proteínas implicadas, los mecanismos moleculares que subyacen a las diferentes formas de degeneración retiniana aún no son muy bien comprendidos. El limitado conocimiento de los procesos moleculares que llevan a la pérdida de fotorreceptores dificulta la intervención terapéutica, que está quedándose rezagada, y los abordajes de mutaciones independientes se ven pues como abordajes más factibles para restablecer la visión. Entre estos métodos, el trasplante de fotorreceptores cultivados in vitro está atrayendo mucha atención.

Se han aislado células con características de progenitores retinianos con el objetivo de desarrollar tratamientos de reposición para la retina. Los progenitores retinianos pueden ser purificados de la retina embrionaria e inducidos a diferenciarse hacia fotorreceptores y otros tipos de células neuronales retinianas. Lo que es más importante, se han identificado células madre en la región marginal del ojo adulto y pueden derivarse células madre de la retina y cultivarse in vitro como neuroesferas pigmentadas a partir del cuerpo ciliar murino y humano adulto (1) y del iris (2). Es de interés que el aislamiento de células madre del cuerpo ciliar ha sido descrito a partir de ojos de donantes de hasta 70 años de edad, lo cual indica la posibilidad de utilizar los tejidos del banco de ojos para obtener células madre para terapia regeneradora. En segundo lugar, las células madre derivadas del cuerpo ciliar adulto poseen un muy buen potencial para dar lugar a altos porcentajes de células similares a fotorreceptores (3). En los últimos años varias cuestiones importantes han sido objeto de investigación en este campo. Un primer aspecto es encontrar la fuente de células humanas apropiadas. En segundo lugar, la fuente de células debería ser cultivada bajo condiciones apropiadas en ausencia de capas nutritivas, FBS, gel matriz no caracterizado que pueda inducir la expresión de antígenos inmunogénicos. En tercer lugar, los cultivos deberían ser lo menos heterogéneos posibles para evitar que las células tomaran otros destinos distintos al de fotorreceptores. Esto abre varios problemas que precisan ser resueltos para poder desarrollar un sistema que pueda ser trasladado a los pacientes: las prioridades serán la amplificación de las células en cultivo para incrementar la cantidad de progenitores de fotorreceptores aptos para el trasplante celular. En segundo lugar, necesitamos idear un sistema de diferenciación y selección para purificar fotorreceptores de los RPE y otros tipos celulares que pueden diferenciarse in vitro. El obstáculo más importante para conseguir un trasplante de células retinianas terapéuticamente eficiente es la necesidad de disponer de grandes cantidades de

\footnotetext{
$1 \mathrm{PhD}$, Profesora asociada de biología molecular.

Departamento de Ciencias Biomédicas, Universidad de Módena y Reggio Emilia, via G. Campi, 28741100 Módena, Italia.

E-mail: valeria.marigo@unimore.it
} 
células para restablecer la visión. Debido a la limitada disponibilidad de células de los tejidos humanos adultos, las células madre embrionarias son vistas también como una posible fuente de fotorreceptores. Se han descrito varios intentos de generar neuronas retinianas a partir de células madre embrionarias. Los más recientes de dichos artículos mostraban diferenciación de células capaces de expresar rodopsina a partir de células madre embrionarias humanas mediante un tratamiento con un medio formulado definido (4). Estudios previos habían comunicado ya diferenciación de las células madre embrionarias hacia células similares a fotorreceptores, pero estaban basados en experimentos de co-cultivo con tejido retiniano embrionario o adulto. Estos métodos estaban lejos de poder tener aplicación terapéutica debido a que es requisito para trasladar los protocolos a los pacientes el evitar los aditivos derivados de animales en los medios de cultivo.

Hasta la fecha, los estudios de trasplantes no han proporcionado evidencia convincente sobre la maduración de células injertadas hacia fotorreceptores y su integración en las redes retinianas para permitir la visión. Sin embargo, los muy prometedores logros en trasplantes sugieren que este campo está avanzando y que el injerto celular es un potencial tratamiento que necesita ser explotado para las degeneraciones retinianas. La literatura disponible hasta ahora sugiere que el resultado del trasplante se ve afectado por diversas variables, tales como las propiedades y la homogeneidad de las células trasplantadas, el estadio de maduración, el punto de inyección y la matriz extracelular del tejido receptor. Evidencia reciente indica que el injerto en una retina en degeneración puede ser más efectivo si se emplean precursores post-mitóticos de fotorreceptores en lugar de progenitores retinianos muy inmaduros o fotorreceptores completamente diferenciados (5). Esto sugiere que una célula necesita ser un precursor de fotorreceptor para ser capaz de responder a los impulsos locales en el tejido receptor y de integrarse en la retina con éxito. La disponibilidad de células en distintos estadios de desarrollo puede abrir nuevas estrategias de trasplante que puedan ser empleadas en la retina degenerativa.

Finalmente, es necesario tener en cuenta que ninguno de los trabajos que se ocupan de trasplantes celulares publicados hasta ahora proporciona una evidencia convincente de la funcionalidad de las células trasplantadas. La definición de diferenciación a fotorreceptor se basaba en la expresión de genes específicos y proteínas. La funcionalidad y la respuesta a la luz no han sido nunca demostradas ni in vivo ni in vitro tras el trasplante. Esto es una limitación de la mayoría de los estudios de trasplantes de retina y se debe fundamentalmente al bajo número de células integradas en las que la funcionalidad no puede ser medida con los análisis clásicos de electrorretinograma y potenciales evocados.

A lo largo de los próximos cinco años continuaremos viendo progresos en el campo de la diferenciación de células madre. Ciertamente, las cuestiones éticas influirán en esta investigación. Además, se han de superar muchos obstáculos biológicos y tecnológicos antes de que las terapias celulares puedan aplicarse a los pacientes. Creo que el problema más importante será la identificación de una fuente de células humanas apropiada para dar lugar a un cultivo homogéneo de fotorreceptores diferenciados funcionales. En segundo lugar, un trasplante celular en la retina humana requerirá un gran número de células para que sea efectivo restaurando la visión. La disponibilidad de la fuente celular y la posibilidad de expansión de las células in vitro antes del trasplante serán altas prioridades en este campo de investigación.

\section{BIBLIOGRAFÍA}

1. Coles BL, Angénieux B, Inoue T, Del Rio-Tsonis K, Spence JR, McInnes RR, et al. Facile isolation and the characterization of human retinal stem cells. Proc Natl Acad Sci U S A 2004; 101: 15772-15777.

2. Haruta M, Kosaka M, Kanegae Y, Saito Y, Inoue T, Kageyama $R$, et al. Induction of photoreceptor-specific phenotypes in adult mammalian iris tissue. Nat Neurosci 2001; 4: 1163-1164.

3. Giordano F, De Marzo A, Vetrini F, Marigo V. Fibroblast growth factor and epidermal growth factor differently affect differentiation of murine retinal stem cells in vitro. Mol Vis 2007; 13: 1842-1850.

4. Osakada F, Ikeda H, Mandai M, Wataya T, Watanabe K, Yoshimura $N$, et al. Toward the generation of rod and cone photoreceptors from mouse, monkey and human embryonic stem cells. Nat Biotechnol 2008; 26: 215-224.

5. MacLaren RE, Pearson RA, MacNeil A, Douglas RH, Salt TE, Akimoto $M$, et al. Retinal repair by transplantation of photoreceptor precursors. Nature 2006; 444: 203-207. 